\title{
Sleep Characteristics and Risk Factors of Korean Esports Athletes: An Exploratory Study
}

\author{
Sangha Lee, PhD ${ }^{1}$, Daniel Bonnar, MPsych², Yeji Kim, BA ${ }^{3}$, Yoojin Lee ${ }^{3}$, \\ Sunkyung Lee ${ }^{4}$, Michael Gradisar, $\mathrm{PhD}^{2}$, Sooyeon Suh, PhD, DBSM ${ }^{3}$ \\ 'Department of Psychiatry, Ajou University School of Medicine, Suwon, Korea \\ ${ }^{2}$ College of Education, Psychology and Social Work, Flinders University, Adelaide, Australia \\ ${ }^{3}$ Department of Psychology, Sungshin Women's University, Seoul, Korea \\ ${ }^{4}$ Department of Psychology, Korea University, Seoul, Korea
}

\author{
Received: November 24, 2020 \\ Revised: December 13, 2020 \\ Accepted: December 15, 2020 \\ Correspondence \\ Sooyeon Suh, PhD, DBSM \\ Department of Psychology, \\ Sungshin Women's University, \\ 2 Bomun-ro 34da-gil, Seongbuk-gu, \\ Seoul 02844, Korea \\ Tel +82-2-920-7215 \\ Fax +82-2-920-2040 \\ E-mail alysuh@sungshin.ac.kr \\ ORCID \\ Sangha Lee \\ https://orcid.org/0000-0002-7042-2052 \\ Daniel Bonnar \\ https://orcid.org/0000-0001-7528-3023 \\ Yeji Kim \\ https://orcid.org/0000-0001-6113-8116 \\ Yoojin Lee \\ https://orcid.org/0000-0002-5994-3420 \\ Sunkyung Lee \\ https://orcid.org/0000-0003-2231-7247 \\ Michael Gradisar \\ https://orcid.org/0000-0002-5146-2657 \\ Sooyeon Suh \\ https://orcid.org/0000-0003-0644-8634
}

(C) This is an Open Access article distributed under the terms of the Creative Commons Attribution Non-Commercial License (https://creativecommons.org/licenses/by-nc/4.0) which permits unrestricted non-commercial use, distribution, and reproduction in any medium, provided the original work is properly cited.
Background and Objective Although sleep is a potentially important determinant of performance in esports, there have been no published data on the sleep behavior of professional esports athletes. The aim of this study is to investigate sleep aspects and sleep risk factors in esports athletes.

Methods Thirty-four esports athletes were compared with 21 nonathletes from the general population to assess their sleep patterns and mood. Study 1 is a quantitative study with a 2 -week observation period of sleep that was performed after evaluating insomnia severity, daytime sleepiness, sleep knowledge, and mood state. During the sleep observation period, participants recorded sleep diaries. In study 2, qualitative research was conducted with in-depth interviews from 6 participants.

Results The esports athlete group reported significantly delayed sleep phase compared to the nonathlete group $(\mathrm{d}=2.10$ hours, $\mathrm{p}<0.001)$. The esports athlete group reported significantly lower sleep quality and scores for feeling refreshed upon awakening, higher depression scores and significantly higher proportion of individuals with clinical symptoms of depression compared to the nonathlete group (ps $<0.01$ ). In study 2 , six themes emerged from the interviews: sleep risk factors, sleep protective factors, lifestyle, stressors, organizational management, and demands for sleep/ psychological intervention.

Conclusions The professional esports athletes showed more depressed mood and more delayed sleep phase compared to the non-athletes. A wide range of interventions tailored to esports athletes should be developed and implemented on both individual and organizational levels.

Sleep Med Res 2020;11(2):77-87

Key Words Esports, Sleep, Mixed-method research, Risk factors.

\section{INTRODUCTION}

Esports (electronic sports) refers to a new type of sports competition in which individuals or teams play a video game competitively. The esports industry is now one of the most rapidgrowing industries, and professional esports athletes have become role models for adolescents. It has been reported that the global esports revenues are projected to grow to $\$ 1.1$ billion by 2020, with an estimated 495 million global viewers for esports events [1].

In contrast to the growth of esports as an industry, management and support for esports athletes remain underdeveloped-especially in the domain of mental health. A previous study reported that $63 \%$ of participants had worse health than before they became esports athletes, with a majority of esports them reporting stress-related disorders, depression, anxiety disorders, and insomnia [2]. However, the reasons for increased risk of psychological issues in esports athletes remains unexplored. To date, to the best of our knowledge, there have been no 
empirical studies investigating psychological and sleep-related problems of esports athletes comparing them to nonathlete counterparts $[3,4]$.

Sleep is an important factor that may affect the performance and mental health of esports athletes $[5,6]$. Sleep has been shown to impair a broad spectrum of cognitive functions (e.g., attention, working memory, executive functioning) $[7,8]$ and increase negative emotions [9]. The negative effects of sleep deprivation on mental health have been repeatedly confirmed through various prior studies (e.g., sleeping 6 hours a day for a week resulted in fatigue and overall mood degradation) [7]. Given the effect of sleep on mood and performance [10] and the high burnout rate of esports athletes, this finding should be considered important [11]. In addition, esports athletes may be at an increased risk of sub-optimal sleep due to long training hours, high consumption of caffeinated beverages, frequent travel to different time zones due to matches, and the nature of competitive esports (e.g., precompetition worries, gaming culture) $[3,4]$, which could therefore also compromise performance and mental health.

Using quantitative research, it is possible to examine the overall status and factors, of esports athletes' sleep patterns and mental health. However, quantitative research does not 1) sufficiently inform us about the underlying issues esports athletes experience in preventing sleep problems, 2) the context in which they respond, and 3) the thoughts and actions that control their responses [12]. In particular, sleep is influenced by both the psychological traits of individuals and external environmental factors. For example, cognitive processes as outlined by Harvey [13], including selective attention and monitoring, distorted perception of sleep and daytime deficits, erroneous beliefs, and counterproductive safety behaviors, can worsen sleep. Additionally, environmental factors such as noise, excessive light, and stimulant use can also negatively impact sleep outcomes [14]. To reveal specific in-depth perceptions and experiences, qualitative research is needed to explore participants' lifestyles, relationships, occupational characteristics, emotions, and subjective recognition. Indeed, there are benefits from using a mixed-methods design (i.e., combining quantitative and qualitative research methods) as they provide insights through quantitative analysis and rich information when converging on the same research questions [15].

Therefore, this study aims to promote a diverse and in-depth understanding of esports athletes' sleep experiences through mixed-methods research. The current study aims to identify the characteristic sleep patterns of and risk factors among Korean esports athletes and to examine the relevance of these features to athletes' emotions. These variables of interest will be compared against a nonathlete group. These investigations may establish basic data on the overall sleep of esports athletes and provide information about the relevance of sleep and emotions. In addition, we expect to provide basic data for developing sleep interventions for esports athletes in the future.

\section{STUDY 1: QUANTITATIVE STUDY OF SLEEP IN ESPORTS ATHLETES}

\section{METHODS}

\section{Subjects}

We contacted 5 professional teams to participate in the study from August to December 2019. A description of the study was provided to prospective participants after which voluntary consent was obtained. All tests were conducted in each team's living headquarters. Fifty-five males (average age, $20.41 \pm 2.40$ years; age range, $16-25$ years) participated in study 1 . Thirty-four Korean elite esports athletes playing in professional leagues were compared to 21 age- and sex-matched nonathletes. Participants under treatment for sleep disorders and those suffering from other psychiatric disorders were excluded as determined by their medical histories and prior phone interviews. Ethics approval was obtained from Sungshin Women's University Institutional Review Board (No. of Approval: SSWUIRB 2019-030-001).

\section{Procedure}

The current study examined two weeks of sleep patterns for all participants. Self-report questionnaires were conducted at baseline, and all subjects were asked to record sleep diaries for 2 weeks. After 2 weeks of sleep monitoring, participants were provided with brief individual feedback for compensation.

\section{Measures}

\section{Sleep pattern evaluation tool}

\section{Sleep diary}

Sleep diaries were collected for 2 weeks to analyze participants' sleep patterns. The following sleep indices were collected through the sleep diaries: bedtime (BT), lights outs (LO), sleep onset (SO), sleep onset latency, wake after sleep onset (WASO), waking time (WT), time out of bed (TOB), sleep quality (SQ), time in bed (TIB), total sleep time (TST), sleep efficiency (SE) and feeling refreshed upon awakening (FR).

\section{Self-report psychological evaluation tool}

\section{Perceived Stress Scale}

This scale consists of two separate subfactors including positive perception and negative perception. Positive perception measures the degree of awareness when individuals were not overwhelmed by a situation and recognized the predictability of and their own control over what happened in their environment. Negative perception measures stress levels when individuals perceive an overwhelming situation that is unpredictable and out of control. A total of 10 questions were scored from 0 (= not 
at all) to 4 (= very often). The total score ranges from 0 to 40 . The internal consistency (Cronbach's $\alpha$ ) in this study was 0.87 .

\section{State-Trait Anxiety Inventory-State}

To estimate the level of anxiety experienced by esports athletes, the State-Trait Anxiety Inventory-State (STAI-X-1) was used. The scale includes 40 questions, 20 for measuring state anxiety, and 20 for measuring trait anxiety. Considering the research purpose, which is measuring anxiety as a sleep-related condition and not as a personal trait, only the state anxiety test was used among the questionnaires. Each item was scored with a 4-point Likert scale from 1 to 4 , and a total score (ranging from 20-80) was calculated by summing individual item scores, with higher scores indicating greater levels of state anxiety. The internal consistency (Cronbach's $\alpha$ ) in this study was 0.85 .

\section{Center for Epidemiologic Studies Depression Scale}

The Center for Epidemiologic Studies Depression Scale (CESD) is a self-report scale to screen for depression [16]. The CES-D is useful as a simple screening test for clinical depression patients and is frequently used since it makes it easier to measure depression in the general population or patients who are experiencing physical pathology [16]. There are 20 items that use a 4-point Likert scale ( 0 to 3 ). Items are summed to generate a total score (ranging from 0-60), with higher total scores indicating more severe levels of depression. In this study, participants who scored more than 16 points were regarded as a high-risk group. The internal consistency (Cronbach's $\alpha$ ) in this study was 0.96 .

\section{Insomnia Severity Index}

The Insomnia Severity Index (ISI) consists of a 7-item fivepoint Likert scale $(0-4)$ that measures the severity of insomnia experienced during the previous two weeks, satisfaction with current sleep, degree to which daytime functions are interrupted by sleep problems, and worries about sleep [17]. The total ISI score ranges from 0 to 28 , and a higher score indicates more severe insomnia. A cut-off score of 10 had $86.1 \%$ sensitivity and $87.7 \%$ specificity for detecting insomnia cases in community samples [18]. The internal consistency (Cronbach's $\alpha$ ) in this study was 0.80 .

\section{Sleep knowledge}

Sleep and performance knowledge was measured using a quiz adapted from Bonnar et al. [19]. The quiz consisted of a total of 16 items that identify the level of general knowledge about sleep and performance [e.g., "Most young adults (aged 18-25 years) need seven to nine hours of sleep a day"]. Participants answered "true," "false" or "don't know." Correct answers were scored 1 and incorrect and "don't know" responses as 0 . Individual item scores were summed to generate a total score out of 16 , with higher total scores indicating greater knowledge.

\section{Pediatric Daytime Sleepiness Scale}

The Pediatric Daytime Sleepiness Scale (PDSS) is an 8-item measure of daytime sleepiness that uses a 5-point Likert scale ranging from 0 to 4 [20]. It was originally invented to measure daytime sleepiness in children and adolescents but was chosen over other popular sleepiness scales (e.g., the Epworth Sleepiness Scale) because its items show greater face validity (i.e., questions aimed at morning sleepiness that are typically experienced by participants in the age range of esports athletes, i.e., adolescents and young adults). The wording of items 1 and 2 was altered to increase their relevance to esports athletes because the original items were school related and none of the participants were attending school. A score of more than 15 points indicates excessive weekday sleepiness [21]. The scale has been validated for use in studies of children, adolescents, and young adults [22]. The internal consistency (Cronbach's $\alpha$ ) in the study by Drake et al. [20] was 0.80 , and it is 0.62 in this study.

\section{Statistics}

Data were analyzed using the Statistical Package for the Social Sciences (SPSS) version 25.0 (IBM Corp., Armonk, NY, USA). Descriptive statistics including means and standard deviations were used to summarize variables. For data composed of continuous variables, t-test or analysis of variance was used, and for the response rate, a chi-square test was used.

\section{RESULTS}

\section{Demographics}

Thirty-four esports athletes of two major esports genres in Korea [Multiplayer Online Battle Arena (MOBA) and First Person Shooter (FPS)] were recruited from a total of five professional teams. They were all males who played an average of 13.56 $( \pm 1.63)$ hours per day. The mean age difference between the esports athlete group $(20.41 \pm 2.40$ years $)$ and nonathlete group $(21.95 \pm 2.92$ years $)$ was not significant. There were 3 adolescents included in the esports athlete group, but no adolescents in the control group. There were also no differences in their body mass index and caffeine consumption. Demographic information can be found in Table 1 .

\section{Sleep Characteristics}

Sleep characteristics of esports athletes derived from the sleep diaries were as follows: the mean TST of esports athletes was 436 ( \pm 73$)$ minutes, which was 27 minutes longer than that in the nonathlete group, but there was no significant difference. The average BT of esports athletes was 4:04 a.m., which was significantly later than that of nonathletes at 2:18 a.m. $(\mathrm{t}=5.588$, $\mathrm{p}<0.001)$. Lights off $(\mathrm{t}=4.887, \mathrm{p}<0.001)$ and SO $(\mathrm{t}=6.026, \mathrm{p}<$ 0.001 ) times of esports athletes were also significantly later than the average times for the nonathlete group. The number of awak- 
Table 1. Demographic information of participants $(n=55)$

\begin{tabular}{|c|c|c|c|}
\hline Variable & Esports athlete & Nonathletes & p-value \\
\hline Age (years) & $20.41 \pm 2.40$ & $21.95 \pm 2.92$ & 0.050 \\
\hline BMI $\left(\mathrm{kg} / \mathrm{m}^{2}\right)$ & $24.24 \pm 5.39$ & $23.50 \pm 2.93$ & 0.580 \\
\hline $\begin{array}{l}\text { Average daily game time } \\
\text { (game playing hours/day) }\end{array}$ & $13.56 \pm 1.63$ & $1.36 \pm 1.02$ & $<0.01^{*}$ \\
\hline Sex, male & $34(100)$ & $21(100)$ & \\
\hline \multicolumn{4}{|l|}{ Age } \\
\hline 10 's & $10(29.4)$ & $5(20.8)$ & \\
\hline 20 's & $24(70.6)$ & $16(66.7)$ & \\
\hline Caffein consumption & $21(61.8)$ & $13(54.2)$ & $0.536^{\dagger}$ \\
\hline
\end{tabular}

Data are presented as mean \pm standard deviaion or $\mathrm{n}(\%)$.

${ }^{*} \mathrm{p}<0.01$. ${ }^{\dagger}$ Chi-square test.

Table 2. Subjective sleep patterns of esports athletes compared to non-esports athletes

\begin{tabular}{lccr}
\hline \multicolumn{1}{c}{ Variable } & $\begin{array}{c}\text { Esports athletes } \\
(\mathrm{n}=34)\end{array}$ & $\begin{array}{c}\text { Non-esports } \\
\text { athletes } \\
(\mathrm{n}=21)\end{array}$ & p-value \\
\hline TST (minutes) & $436 \pm 73$ & $415 \pm 12$ & 0.182 \\
BT (hh:mm) & $4: 04 \pm 0: 59$ & $2: 18 \pm 1: 21$ & $<0.01^{*}$ \\
LO (hh:mm) & $4: 35 \pm 1: 03$ & $2: 57 \pm 1: 25$ & $<0.01^{*}$ \\
SOL (minutes) & $22.51 \pm 24.60$ & $13.05 \pm 7.32$ & 0.093 \\
SO (hh:mm) & $5: 04 \pm 1: 00$ & $2: 58 \pm 1: 11$ & $<0.01^{*}$ \\
WASO (minutes) & $12.39 \pm 21.80$ & $9.72 \pm 7.62$ & 0.593 \\
NWAK (times) & $1.25 \pm 1.71$ & $1.31 \pm 1.25$ & 0.875 \\
WT (hh:mm) & $12: 13 \pm 0: 47$ & $10: 09 \pm 1: 29$ & $<0.01^{*}$ \\
TOB (hh:mm) & $12: 33 \pm 0: 42$ & $10: 13 \pm 1: 31$ & $<0.01^{*}$ \\
TIB (minutes) & $529 \pm 71$ & $494 \pm 84$ & 0.222 \\
SE (\%) & $82.55 \pm 9.46$ & $84.53 \pm 5.83$ & 0.383 \\
Sleep quality & $2.75 \pm 0.46$ & $3.34 \pm 0.67$ & $<0.01^{*}$ \\
Freshness & $2.63 \pm 0.45$ & $3.10 \pm 0.54$ & $0.002^{*}$ \\
\hline Data & &
\end{tabular}

Data are presented as mean \pm standard deviaion.

${ }^{*} \mathrm{p}<0.01$.

TST: total sleep time, BT: bed time, LO: lights outs, SOL: sleep onset latency, SO: sleep onset, WASO: wake after sleep onset, NWAK: number of awakening, WT: wake-up time, TOB: time out of bed, TIB: time in bed, SE: sleep efficiency.

ening of esports athletes was $1.25( \pm 1.71)$ times on average during sleep, and the average WASO time was 12.39 ( \pm 21.80$)$ minutes; both results were not significantly different from those of nonathletes (Table 2). The average WT of esports athletes was 12:13 p.m. ( \pm 47 minutes), which was significantly more delayed than that of the nonathletes $(10: 09 \pm 89$ minutes; $\mathrm{t}=6.681, \mathrm{p}<$ 0.001 ), and the TOB after awakening among esports athletes was also delayed by more than two hours compared with the nonathletes $(\mathrm{t}=7.028, \mathrm{p}<0.001)$. The SQ $(\mathrm{t}=-3.156, \mathrm{p}<0.001)$, which was measured on a 5-point Likert scale, and the FR $(\mathrm{t}=$ $-2.857, \mathrm{p}<0.001)$ of esports athlete group were rated signifi-
Table 3. Sleep and clinical indices for esports athletes and nonathletes

\begin{tabular}{|c|c|c|c|}
\hline Variable & $\begin{array}{l}\text { Esports athletes } \\
\qquad(\mathrm{n}=34)\end{array}$ & $\begin{array}{c}\text { Non-esports } \\
\text { athletes } \\
(\mathrm{n}=21)\end{array}$ & p-value \\
\hline \multicolumn{4}{|l|}{ PDSS } \\
\hline Mean \pm SD & $16.65 \pm 5.13$ & $14.43 \pm 5.31$ & 0.135 \\
\hline $\mathrm{n}$ of high risk (\%) & $24^{\dagger}(70.6)$ & $11(52.4)$ & $0.173^{\ddagger}$ \\
\hline \multicolumn{4}{|l|}{ ISI } \\
\hline Mean \pm SD & $8.97 \pm 4.13$ & $8.05 \pm 5.27$ & 0.508 \\
\hline n of high risk (\%) & $14^{\dagger}(41.2)$ & $7(33.3)$ & $0.561^{\ddagger}$ \\
\hline \multicolumn{4}{|l|}{ STAI-X-1 } \\
\hline Mean \pm SD & $39.09 \pm 11.24$ & $36.10 \pm 9.67$ & 0.300 \\
\hline $\mathrm{n}$ of high risk (\%) & $4^{\dagger}(11.8)$ & $2(9.5)$ & $0.796^{\ddagger}$ \\
\hline \multicolumn{4}{|l|}{ CES-D } \\
\hline Mean \pm SD & $21.29 \pm 14.11$ & $9.76 \pm 8.28$ & $0.001^{*}$ \\
\hline n of high risk (\%) & $22^{\dagger}(64.7)$ & $3(14.3)$ & $<0.01^{* \ddagger}$ \\
\hline \multicolumn{4}{|l|}{ PSS } \\
\hline Mean \pm SD & $16.09 \pm 1.64$ & $16.00 \pm 0.92$ & 0.960 \\
\hline \multicolumn{4}{|l|}{ Sleep quiz } \\
\hline Mean \pm SD & $46.35 \pm 13.94$ & $55.93 \pm 11.73$ & $0.010^{*}$ \\
\hline
\end{tabular}

${ }^{*} \mathrm{p}<0.01 .{ }^{\dagger}$ Derived only when cut-off is present. ${ }^{\ddagger}$ Chi-square test. SD: standard deviation, PDSS: Pediatric Daytime Sleepiness Scale, ISI: Insomnia Severity Index, STAI-X-1: the State-Trait Anxiety Inventory-State, CES-D: Epidemiologic Studies Depression Scale, PSS: Perceived Stress Scale.

cantly lower than the nonathlete group.

\section{Insomnia, Daytime Sleepiness, and Emotional Regulation}

Information from self-report questionnaires is presented in Table 3. There were no significant differences in either the severity of insomnia or daytime sleepiness among esports athletes and nonathletes. However, the mean daytime sleepiness score among esports players exceeded the cut-off (15 points), indicating that esports athletes experienced high levels of sleepiness during the day. Esports athletes scored significantly higher in depression $(t=3.818, p<0.01)$, with a higher proportion of esports athletes scoring above the clinical cut-off value (CES-D > 16) for depression than the proportion of nonathletes $(64.7 \%$ vs. $14.3 \%, \mathrm{p}<0.001)$. However, the levels of anxiety (STAI-X-1) and perceived stress (Perceived Stress Scale) among esports athletes were not significantly different from those among nonathletes. The scores of the sleep quiz, which measures general knowledge about sleep, were significantly lower in esports players than in nonathletes ( 46.35 vs. 55.93 , respectively; $\mathrm{p}<0.01$ ). 


\section{STUDY 2: QUALITATIVE STUDY OF ESPORTS' PLAYERS AND COACHES' SLEEP}

\section{METHODS}

\section{Data Collection}

Three volunteers from the participants of study 1 and three of their coaches attended the study 2 underwent the semistructured interview. We reviewed the baseline questionnaires, which described their experiences and thoughts, examined the esports athletes' sleep patterns and asked additional questions. In the process of organizing the questions, the questionnaire used in an existing phenomenological qualitative study of sleep disorders was referenced [23]. Interview instructions were developed, and the interviews were supervised by a clinical psychologist who is also a behavioral sleep medicine specialist.

Each of the questions presented in the interview addressed particular topics or areas including health conditions, relationship, work, and life as an esports athlete, and sleep. Some examples of the seed questions used to prompt the interviews can be seen in Table 4 . The progression of the questions was not equivalent for all participants and varied based on interviews and participants' responses. However, based on the interview instructions, researchers could gather similar forms of information from all participants. In this way, researchers could save time and de- crease the collection of unnecessary information compared with unstructured interviews [24]. Researchers could create or add questions even if they were not included in the guidelines [25]. In this study, the analysis method of Giorgi [26] was used to explore the meaning and nature of risk factors associated with sleep patterns of esports athletes. The stages of analysis method based on Giorgi are: 1) read the description for the sense of the whole, 2) divide the description into meaning unit, 3) transform meaning units into best disciplinary expression, 4) synthesize transformed meaning units into structure. NVivo12 (QSR International, Melbourne, Australia) was used to analyze the qualitative data.

\section{RESULTS}

After transcribing the recorded files, 191 meaning units were derived from the analysis of the data. Ultimately, 138 final meaning units were obtained. These were classified into 30 components according to similar attributes and organized into the following 6 categories: 'life of an esports athlete,' 'stressor,' 'sleep risk factor,' 'sleep protective factor,' 'need for intervention,' and 'team management.' The examples of participant quotations by category are shown in Table 5 and the structure of sleep and sleep risk factors and life factors of esports athletes is shown in Fig. 1.

Table 4. Seed questions used in the semi-structured interviews

\begin{tabular}{|c|c|}
\hline Stage & Examples of seed questions \\
\hline 1. Introduction & How do you feel about the new season with new members? \\
\hline \multirow[t]{17}{*}{ 2. Facilitation } & 1) Topic 1: Health \\
\hline & How do you take care of your health? \\
\hline & Are you participating in any health care programs? \\
\hline & If health care programs are provided, what kind of assistance would you like to receive? \\
\hline & $\begin{array}{l}\text { You seem to go to bed very late and wake up in the middle of the day, did you have that kind of lifestyle before } \\
\text { becoming a pro? }\end{array}$ \\
\hline & 2) Topic 2: Relationships \\
\hline & $\begin{array}{l}\text { Since teamwork is important for the game, the relationship between teammates is very important. Which player are you } \\
\text { most close with? How do you solve conflicts? }\end{array}$ \\
\hline & You seem to stay together for training almost all day of the year, how often do you meet your family? \\
\hline & $\begin{array}{l}\text { Could you tell me if you've ever had a hard time with coaches, players, or others, or if you've ever seen a player who } \\
\text { experienced this situation? }\end{array}$ \\
\hline & 3) Topic 3: Job and life \\
\hline & What kind of value do you think an esports athlete has? \\
\hline & Do you have any special plans after retiring? \\
\hline & What is the best part and the hardest part? \\
\hline & 4) Topic 4: Sleep \\
\hline & How have you been sleeping lately? Do you have any particular concerns about sleeping? \\
\hline & If a sleep enhancement program for esports athlete is provided, would you like to get help particularly? \\
\hline & If a stress management program for e-sports athlete is made, would you like to participate? \\
\hline 3. Closing & Is there anything else you'd like to add? \\
\hline
\end{tabular}


Table 5. Examples of participant quotations by category

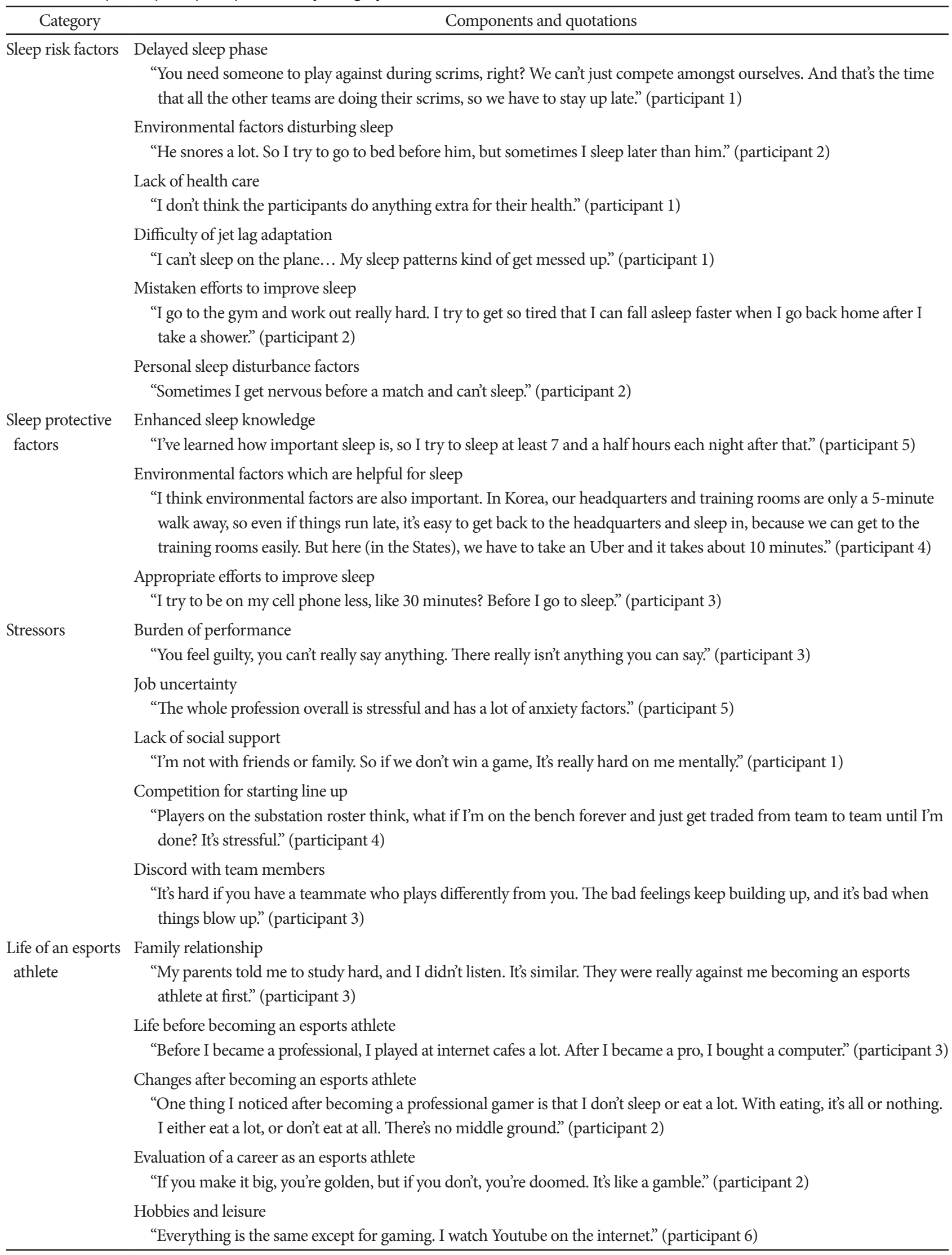


Table 5. Examples of participant quotations by category (continued)

\begin{tabular}{|c|c|}
\hline Category & Components and quotations \\
\hline \multirow{4}{*}{$\begin{array}{l}\text { Team } \\
\text { management }\end{array}$} & $\begin{array}{l}\text { Team atmosphere } \\
\text { "The psychological parts do have a big effect. If everyone isn't motivated, the team ambience is contagious and can cause } \\
\text { everyone to become unmotivated." (participant } 1 \text { ) }\end{array}$ \\
\hline & $\begin{array}{l}\text { Relationship with fans } \\
\text { "It makes me think that I can give hope to them and give them happiness, and I think it really motivates me." (participant 1) }\end{array}$ \\
\hline & $\begin{array}{l}\text { Weak management skills } \\
\text { "If players fight, the coaches do get involved. They try to get them to make up, and sometimes it works, but most times } \\
\text { it doesn't. When the relationship is beyond repair, the easiest thing the team can do is fire the player from the team." } \\
\text { (participant 4) }\end{array}$ \\
\hline & $\begin{array}{l}\text { Importance of coaching roles } \\
\text { "We know just by the tone of the player's voice when they are giving orders or briefing someone that they are mad at } \\
\text { someone specific. Or that they are angry because they couldn't pull off a play. We've seen it in so many players that it's } \\
\text { easy to catch it. Not just me, but the whole staff.' (participant 4) }\end{array}$ \\
\hline \multirow[t]{5}{*}{$\begin{array}{l}\text { Need for } \\
\text { intervention }\end{array}$} & $\begin{array}{l}\text { Need sleep enhancement programs } \\
\text { "Because most of the players slept through their classes or dropped out of school... it's better to educate them about } \\
\text { sleep with easy content, exposing them repeatedly so they understand the importance of sleep." (participant 5) }\end{array}$ \\
\hline & Need for psychological intervention \\
\hline & $\begin{array}{l}\text { "Can the players get therapy from someone like in the movies? Once in a while we'll get a player who really wants } \\
\text { therapy." (participant 4) }\end{array}$ \\
\hline & $\begin{array}{l}\text { Need to improve communication skills } \\
\text { "I feel communication is really really really hard... The reason why there is a problem with communication is that } \\
\text { they're not very good at listening to one another." (participant 5) }\end{array}$ \\
\hline & $\begin{array}{l}\text { Need to address emotional problems } \\
\text { "They can get angry. Or depressed. You know? I feel they need some hobby to blow off steam or a staff member who } \\
\text { can help with these things." (participant 1) }\end{array}$ \\
\hline
\end{tabular}

\section{Sleep Risk Factors}

Six sleep risk factors were identified in the interviews with esports athletes. The esports athletes display delayed sleep phases due to their training time, which usually ends very late at night, with one participant reporting "individual training continues until 3 a.m. after completing team training at midnight." The athletes and their teams insisted that this time frame was necessary to make the training more efficient. In addition, the sleep environment of the shared headquarters, such as the room temperature, outdoor noise, absence of a health management system, use of the wrong methods to improve sleep quality, and time difference due to away matches were also considered sleep risk factors. The interviewees also considered the tension of the night before a competition, long exposure to light, stress, and caffeinecontaining drinks as sleep risk factors.

\section{Sleep Protective Factors}

Because all the participants from study 1 participated in a sleep education and a feedback session, the effects of those interventions have already been included in the protective factors. Knowledge about the environment that improves sleep quality, proper actions for better sleep quality, and sleep hygiene were identified as protective factors that had a positive effect on sleep quality.
Strategies such as having a more organized lifestyle, improving sleep hygiene, not napping during the daytime, and not using smartphones for more than 30 minutes before going to bed can also improve athletes' sleep quality.

\section{Stressors}

Stress can have a (negative) effect on mental health and sleep quality. Various factors such as fear of the future due to job instability, lack of social support, and competition for the starting line-up (which can cause short-term depression) can cause stress among esports athletes. These factors can cause short-term depression. In addition, personality differences and communication problems with teammates of different nationalities can also cause stress among athletes.

\section{Life of an Esports Athlete}

Esports athletes were usually students before they started their careers, with most athletes choosing to drop out of school to become esports athletes. Most of the athletes experienced opposition from their families, but the level of support from their families was dependent on the success of their careers. The majority of the top-tier (popular) athletes had high job satisfaction, and they were proud of their careers. Esports athletes had pride that 


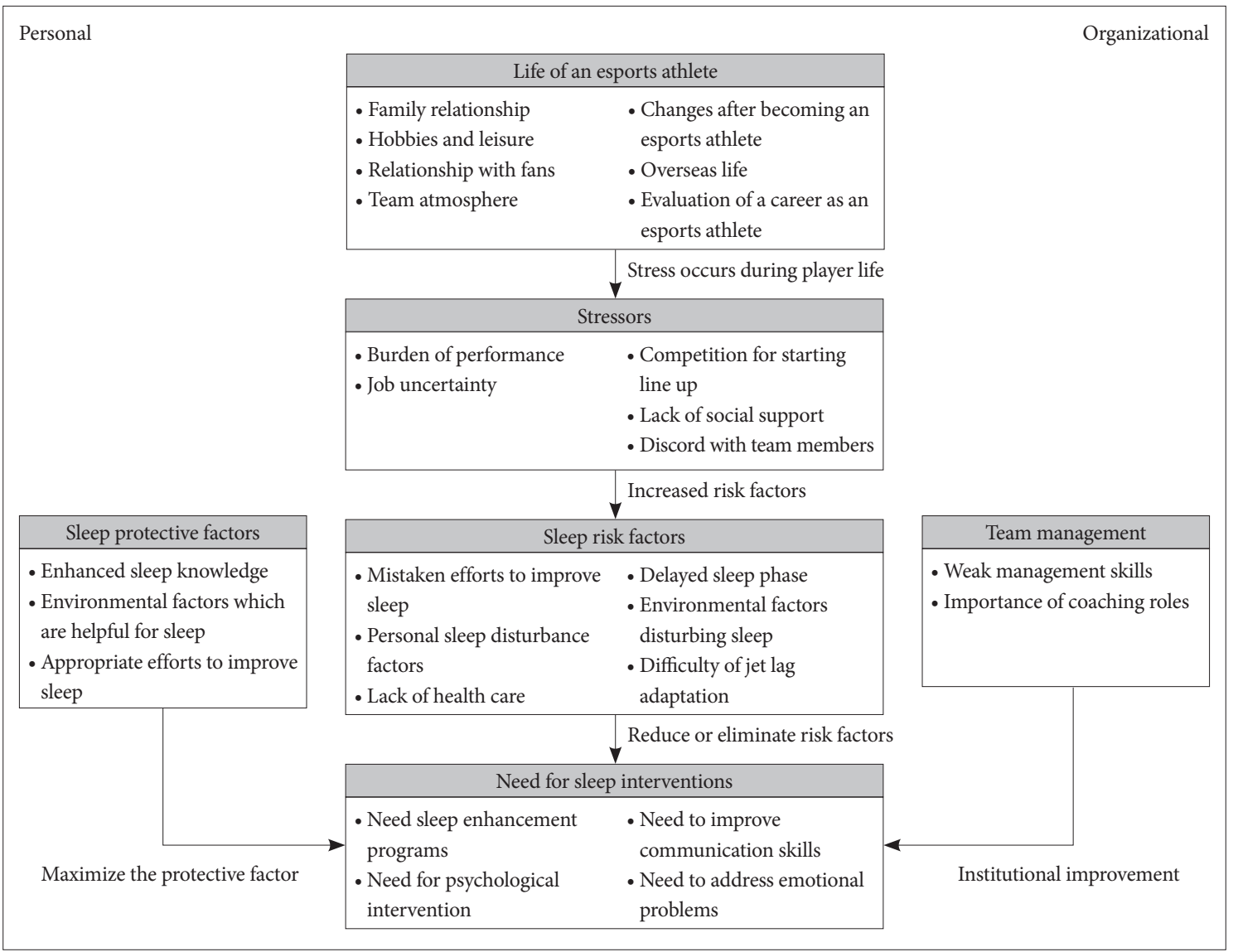

Fig. 1. Structure of sleep and sleep risk factors and life factors of esports athletes.

they had fans and felt responsible for meeting their fans' expectations. In addition, the athletes experienced emotional distress from criticism on social media; furthermore, the atmosphere of the team not only affected the outcome of the game but also the duration of internal team conflicts.

\section{Team Management}

Team management was deeply related to both mental health and sleep problems of esports athletes. Few esports teams have an organized management system or a sufficient number of professional managers. Team management seemed to be heavily affected by the head company's capacity and budget. The role of the team directors and coaches who manage young esports athletes is critical. However, they often lack the professional skills to manage the organization, such as managing conflicts between the athletes. Coaches need to be able to help athletes who are having a difficult time with consultation and proper rest and need to teach them how to deal with criticism with a more flexible mindset.

\section{Need for Interventions}

The need for intervention was mainly mentioned by the coaches. There were demands for education in communication skills, emotional management skills, and sleep improvement programs including psychological counseling. Improving awareness of the importance of good sleep has been addressed as the most helpful factor in sleep improvement programs. It was also suggested that educational methods are needed to suit the athletes' learning abilities. For an intervention to be effective, a rather strong level of recommendation is required, and a system that can be enforced may be needed. The esports athletes thought that psychological counseling was essential and felt that it would be helpful to talk to outside experts about topics that were difficult to discuss with their managers, coaches, or teammates. Communication problems within the team were the most frequently mentioned issues by the coaches, and the need for intervention was emphasized. The causes of communication problems appeared to be that most athletes are young, lack sufficient school education, tend to display some self-centered qualities, and do not have sufficient social skills to resolve conflicts.

\section{DISCUSSION}

This is the first empirical study to examine sleep in Korean esports athletes compared to nonathletes. The aim of the current 
study was to investigate sleep characteristics and sleep risk factors among esports athletes compared with nonathletes. The results from this study indicated that esports athletes had a severely delayed sleep phase compared with their age-matched peers who were nonathletes. While they did not sleep less, esports athletes went to bed an average of more than 1 hour and 40 minutes later than their nonathlete counterparts. The cause of this delayed sleep pattern was explored in study 2 using qualitative methodology.

\section{Sleep Characteristics of Esports Athletes}

In this study, the mean TST was $7.26( \pm 1.21)$ hours, which was not significantly different from the control group. However, this appears to be significantly lower than mean TSTs of esports athletes in other countries. In previous studies, $8.1( \pm 1.2)$ hours sleep in the US [27] and 7.8 ( \pm 1.3) hours in Germany [28] were reported. Considering that adolescents in East Asia (especially in Korea) sleep less than those in the US and European countries [29], it is worthy not only to compare them with the general population in Korea but also to esports athletes from other countries.

The delay in sleep phase of esports athletes seems to be primarily affected by their environment and training schedule. Almost every esports athlete lives in shared headquarters with his or her teammates, and they train together. One of the most important parts of team training is practicing matches with other teams (i.e., scrimmage), which makes it difficult to change sleep schedules. In addition, prolonged use of computers for training (and the use of smartphones before bedtime) delays their sleep timing and makes it difficult for athletes to fall asleep at a normal bedtime.

Esports athletes also reported significantly worse sleep quality compared to their nonathlete counterparts. There are two plausible explanations for this difference. First, qualitative evidence from the present study suggests that some esports athletes may be exposed to environmental factors that disturb sleep (e.g., snoring), leading to a deterioration in subjective sleep quality. Evidence indicates that the sleep environment is strongly linked with adequate sleep quality [30]. One noteworthy implication of this finding is that if a team lives in a shared headquarters, as was the case in our study, then presumably an entire team may be at risk of poor sleep quality if the sleep environment is suboptimal. In addition to sleep environment, poor sleep quality and not feeling refreshed after awakening in the esports athlete group may have been influenced by high levels of depression. Sleep quality is known to be highly correlated with depressive symptoms and stress [31,32]. In this study, the perceived stress level reported by esports athletes was not significantly higher than that of the nonathletes. However, the findings that the average depression score exceeded the clinical cut-off value of 16 and that the rate of the high-risk group for depression reached $64.7 \%$ suggests a high possibility that depression worsened the subjective sleep quality of esports athletes. These high levels of depression are also related to the delayed sleep phase [33]. In a study that examined the relationships among sleep quality, circadian pattern, and emotion in 236 young adults aged approximately 18 years, participants with an evening phase complained of more depressive symptoms [33].

In addition to delayed sleep, our qualitative findings have shown various risk factors for poor sleep in esports athletes. Poor sleep knowledge can act as a perpetuating factor in sleep problems. In the sleep knowledge questionnaire, the average score of the esports athlete group was significantly lower than that of the nonathlete group. Based on misinformation and irrational beliefs, some of the athletes maintained typical persistent behaviors, such as intense training before bedtime [3] or drinking alcohol before bedtime. This suggests that sleep interventions, such as sleep hygiene, may also help improve sleep in this group. In fact, a recent study showed that sleep hygiene education alone helped improve sleep in low socioeconomic groups [34,35].

\section{Interpersonal Factors of Esports Players}

Another problem found through qualitative research was the lack of communication skills among the players. Individuals participating in the interviews of the study 2 reported that most esports athletes are young, are not well-educated, and lack sufficient social skills to resolve conflicts. Despite the importance of teamwork and communication skills in this team sport [36], spending long hours without direct personal contact with other individuals outside of the game may result in limited growth of social skills. Insufficient social skills affect not only daily life but also competition performance, and because most of the athletes' time is spent with teammates, their social relationships can have a significant impact on game performance [37]. Furthermore, communication quality may be affected not only by individuals' communication skills but also by their sleep quality. Players with sub-optimal sleep appear more likely to be emotionally sensitive to negative comments from team members and coaches regarding their performance [38]. Stress is itself a risk factor for poor sleep, but a lack of social support, such as that from family and friends, derived from qualitative research is also an important variable to be addressed. Social support is a protective factor that allows individuals to maintain a sense of wellbeing in stressful situations [39]. Even if stress-coping skills are insufficient, mental health can be maintained if social support is sufficient [40].

\section{Organizational and Environmental Factors in Esports Players}

The role of the organization is important in reducing the stress of esports players. Our results show that esports athletes' stress levels are greatly influenced by the policies and capabilities of their organizations and managers because they live in a group together. Players mainly reported stress factors such as the bur- 
den of the game, anxiety due to an uncertain future, competition for the starting lineup, relationships with their team members, and lack of social support due to camp life. These psychosocial stressors not only reduce sleep quality [41] but can also cause sleep problems [42-45]. In particular, relationships with other team members are often worsened in the course of receiving feedback on the game, which may be the reason that the athletes did not have the opportunity to develop sufficient emotional control skills or social skills, including communication skills. As a result, coaches must intervene in players' conflict situations, but they do not have expertise in conflict mediation or psychological counseling; therefore, the effectiveness of their intervention cannot be guaranteed.

Physical environmental conditions are also directly related to the organization's management capabilities. Sleep hygiene is known to be a protective factor affecting bedtime, sleep latency, and total sleep time [46]. Sleep hygiene is related to several areas of sleep, including behavioral, physiological, and emotional arousal, the sleep environment, and sleep stability [47]. A recent qualitative study on the performance of esports athletes identified a weakness in their emotional regulation ability, lack of trust between peers, and inefficient communication as factors that hinder them from achieving good performance [48]. This is consistent with the qualitative results of this study.

\section{Limitations}

This study has some limitations. First, whilst sleep diaries are considered superior to other forms of self-report (e.g., due to reduced memory bias [49]), it would have been valuable to simultaneously obtain objective sleep data (i.e., wrist actigraphy). Second, sufficient quantitative data on risk factors for poor sleep were not collected. Because specific information on predictable factors, such as caffeine use, smoking, and the timing of smartphone use before bedtime, has not been identified, the relationship between these factors and actual sleep was not confirmed statistically. In follow-up studies, the effect size of risk factors for poor sleep could be additionally identified through the collection of detailed information on such life variables.

\section{Conclusion}

The current study is the first empirical study to evaluate the sleep of Korean esports athletes. Considering the rapidly growing esports industry, research on the mental health of esports players is crucial. The present study can provide a good reference for future researchers exploring this field. Although it was limited to exploratory research, there are various implications for clinical interventions related to the sleep of esports players. A wide range of interventions including sleep education tailored to the level of esports athletes, cognitive behavioral therapy for insomnia (CBTi), social skills training, emotional management, and stress reduction programs should be developed and implemented on both individual and organizational levels.

\section{Acknowledgments}

This work was supported by the Korean Society of Sleep Medicine (KSSM, Korea). The funding body had no role in study design, data collection and analysis, or preparation of the manuscript.

\section{Conflicts of Interest}

The authors have no financial conflicts of interest.

\section{Authors' Contribution}

Conceptualization: Lee Sangha, Suh S. Data curation: Lee Sangha, Kim Y. Formal analysis: Lee Sangha. Funding acquisition: Suh S. Investigation: Lee Sangha, Kim Y, Suh S. Methodology: Lee Sangha. Project administration: Suh S. Supervision: Suh S, Gradisar M. Validation: Gradisar M, Bonnar D. Visualization: Lee S. Writing-original draft: Lee Sangha, Suh S. Writing - review \& editing: Suh S, Bonnar D, Lee Y, Lee Sunkyung.

\section{REFERENCES}

1. Newzoo. 2020 Global esports market report 2020 [cited 2020 Jul 17]. Available from: https://newzoo.com/insights/trend-reports/newzooglobal-esports-market-report-2020-light-version/.

2. Kim CW, Park CY, Kwak HS. A study on the pro-gamer's daily life and perception of e-sports. Journal of Leisure Studies 2006;3:27-46.

3. Bonnar D, Lee S, Gradisar M, Suh S. Risk factors and sleep intervention considerations in esports: a review and practical guide. Sleep Med Res 2019;10:59-66.

4. Bonnar D, Castine B, Kakoschke N, Sharp G. Sleep and performance in Eathletes: for the win! Sleep Health 2019;5:647-50.

5. Zohar D, Tzischinsky O, Epstein R, Lavie P. The effects of sleep loss on medical residents' emotional reactions to work events: a cognitive-energy model. Sleep 2005;28:47-54.

6. Minkel JD, Banks S, Htaik O, Moreta MC, Jones CW, McGlinchey EL, et al. Sleep deprivation and stressors: evidence for elevated negative affect in response to mild stressors when sleep deprived. Emotion 2012; 12:1015-20.

7. Dinges DF, Pack F, Williams K, Gillen KA, Powell JW, Ott GE, et al. Cumulative sleepiness, mood disturbance, and psychomotor vigilance performance decrements during a week of sleep restricted to 4-5 hours per night. Sleep 1997;20:267-77.

8. Taffinder NJ, McManus IC, Gul Y, Russell RC, Darzi A. Effect of sleep deprivation on surgeons' dexterity on laparoscopy simulator. Lancet 1998;352:1191.

9. Pilcher JJ, Huffcutt AI. Effects of sleep deprivation on performance: a meta-analysis. Sleep 1996;19:318-26.

10. Beedie CJ, Terry PC, Lane AM. The profile of mood states and athletic performance: two meta-analyses. J Appl Sport Psychol 2000;12:49-68.

11. Hassan A. Esports players are burning out in their 20s. [cited $2020 \mathrm{Oct}$ 9]. Available from: https:/qz.com/work/1509134/esports-players-areburning-out-in-their-20s-because-of-stress/.

12. Creswell JW, Creswell JD. Research design: qualitative, quantitative, and mixed methods approaches. 5th ed. Thousand Oaks: SAGE Publications, Inc. 2017.

13. Harvey AG. A cognitive model of insomnia. Behav Res Ther 2002;40: 869-93.

14. Harris K, Spiegelhalder K, Espie CA, MacMahon KM, Woods HC, Kyle SD. Sleep-related attentional bias in insomnia: a state-of-the-science review. Clin Psychol Rev 2015;42:16-27.

15. Johnson RB, Onwuegbuzie AJ. Mixed methods research: a research paradigm whose time has come. Educ Res 2004;33:14-26.

16. Radloff LS. The CES-D scale: a self-report depression scale for research in the general population. Appl Psychol Meas 1977;1:385-401.

17. Bastien CH, Vallières A, Morin CM. Validation of the Insomnia Severity Index as an outcome measure for insomnia research. Sleep Med 2001;2:297-307. 
18. Morin CM, Belleville G, Bélanger L, Ivers H. The Insomnia Severity Index: psychometric indicators to detect insomnia cases and evaluate treatment response. Sleep 2011;34:601-8.

19. Bonnar D, Gradisar M, Moseley L, Coughlin AM, Cain N, Short MA. Evaluation of novel school-based interventions for adolescent sleep problems: does parental involvement and bright light improve outcomes? Sleep Health 2015;1:66-74.

20. Drake C, Nickel C, Burduvali E, Roth T, Jefferson C, Pietro B. The pediatric daytime sleepiness scale (PDSS): sleep habits and school outcomes in middle-school children. Sleep 2003;26:455-8.

21. Meyer C, Barbosa DG, Junior GJF, Andrade RD, Silva DAS, Pelegrini A, et al. Proposal of cutoff points for pediatric daytime sleepiness scale to identify excessive daytime sleepiness. Chronobiol Int 2018;35:303-11.

22. Richardson C, Micic G, Cain N, Bartel K, Maddock B, Gradisar M. Cognitive "insomnia" processes in delayed sleep-wake phase disorder: do they exist and are they responsive to chronobiological treatment? J Consult Clin Psychol 2019;87:16-32.

23. Kim W. Sleep disorders in married, female, shift-working nurses. The Korean Journal of Rehabilitation Psychology 2018;25:775-88.

24. Holloway I, Galvin K. Qualitative research in nursing and healthcare. 4th ed. Hoboken: John Wiley \& Sons, Ltd. 2016.

25. King N, Horrocks C. An introduction to interview data analysis. In: King N, Horrocks C, Brooks J. Interviews in qualitative research. 2nd ed. Thousand Oaks: SAGE Publications, Inc 2010;142-74.

26. Giorgi A. The theory, practice, and evaluation of the phenomenological method as a qualitative research procedure. J Phenomenol Psychol 1997;28:235-60.

27. Thomas CJ, Rothschild J, Earnest CP, Blaisdell A. The effects of energy drink consumption on cognitive and physical performance in elite league of legends players. Sports (Basel) 2019;7:196.

28. Rudolf K, Bickmann P, Froböse I, Tholl C, Wechsler K, Grieben C. Demographics and health behavior of video game and eSports players in Germany: the eSports study 2019. Int J Environ Res Public Health 2020;17:1870.

29. Gradisar M, Gardner G, Dohnt H. Recent worldwide sleep patterns and problems during adolescence: a review and meta-analysis of age, region, and sleep. Sleep Med 2011;12:110-8.

30. Caddick ZA, Gregory K, Arsintescu L, Flynn-Evans EE. A review of the environmental parameters necessary for an optimal sleep environment. Build Environ 2018;132:11-20.

31. Wallace DD, Boynton MH, Lytle LA. Multilevel analysis exploring the links between stress, depression, and sleep problems among two-year college students. J Am Coll Health 2017;65:187-96.

32. Paunio T, Korhonen T, Hublin C, Partinen M, Koskenvuo K, Koskenvuo $\mathrm{M}$, et al. Poor sleep predicts symptoms of depression and disability retirement due to depression. J Affect Disord 2015;172:381-9.

33. Tonon AC, Carissimi A, Schimitt RL, de Lima LS, Pereira FDS, Hidal- go MP. How do stress, sleep quality, and chronotype associate with clinically significant depressive symptoms? A study of young male military recruits in compulsory service. Braz J Psychiatry 2020;42:54-62.

34. Rottapel RE, Zhou ES, Spadola CE, Clark CR, Kontos EZ, Laver K, et al. Adapting sleep hygiene for community interventions: a qualitative investigation of sleep hygiene behaviors among racially/ethnically diverse, low-income adults. Sleep Health 2020;6:205-13.

35. Spadola CE, Rottapel RE, Zhou ES, Chen JT, Guo N, Khalsa SBS, et al. A sleep hygiene and yoga intervention conducted in affordable housing communities: pilot study results and lessons for a future trial. Complement Ther Clin Pract 2020;39:101121.

36. Charbonneau D, Wood VM. Antecedents and outcomes of unit cohesion and affective commitment to the Army. Mil Psychol 2018;30:43-53.

37. Kleinert J, Ohlert J, Carron B, Eys M, Feltz D, Harwood C, et al. Group dynamics in sports: an overview and recommendations on diagnostic and intervention. Sport Psychol 2012;26:412-34.

38. Goldstein AN, Walker MP. The role of sleep in emotional brain function. Annu Rev Clin Psychol 2014;10:679-708.

39. Cohen S, Wills TA. Stress, social support, and the buffering hypothesis. Psychol Bull 1985;98:310-57.

40. Seo M, Choi BY, Jo HI. The effect of life stress, stress coping, and social support on mental health. Korean J Couns 2006;7:271-88.

41. Nasermoaddeli A, Sekine M, Hamanishi S, Kagamimori S. Job strain and sleep quality in Japanese civil servants with special reference to sense of coherence. J Occup Health 2002;44:337-42.

42. Frese M, Harwich C. Shiftwork and the length and quality of sleep. J Occup Med 1984;26:561-6.

43. Jacquinet-Salord MC, Lang T, Fouriaud C, Nicoulet I, Bingham A. Sleeping tablet consumption, self reported quality of sleep, and working conditions. Group of Occupational Physicians of APSAT. J Epidemiol Community Health 1993;47:64-8.

44. Kuppermann M, Lubeck DP, Mazonson PD, Patrick DL, Stewart AL, Buesching DP, et al. Sleep problems and their correlates in a working population. J Gen Intern Med 1995;10:25-32.

45. Linton SJ. Does work stress predict insomnia? A prospective study. $\mathrm{Br}$ J Health Psychol 2004;9:127-36.

46. Bartel KA, Gradisar M, Williamson P. Protective and risk factors for adolescent sleep: a meta-analytic review. Sleep Med Rev 2015;21:72-85.

47. Storfer-Isser A, Lebourgeois MK, Harsh J, Tompsett CJ, Redline S. Psychometric properties of the Adolescent Sleep Hygiene Scale. J Sleep Res 2013;22:707-16.

48. Himmelstein D, Liu Y, Shapiro JL. An exploration of mental skills among competitive league of legend players. Int J Gaming Comput Mediat Simul 2017;9:1-21.

49. Buysse DJ, Ancoli-Israel S, Edinger JD, Lichstein KL, Morin CM. Recommendations for a standard research assessment of insomnia. Sleep 2006;29:1155-73. 